\title{
On Research and Practice of Building a Harmonious, Progressive and Professional Team with Technological Innovation as Management Media
}

\author{
Zhang Xilin ${ }^{1, a}$, Xu Shouchen ${ }^{2, b}$ \\ 1. State Grid Jilin Electric Power Company Limited Changchun Power Supply Company , \\ Changchun, 130021, China \\ 2. State Grid the Advanced Training Center, Beijing, 100085, China \\ aemail: xilinzhang@21cn.com, bemail: shouchen-xu@sohu.com
}

Keywords: Power Supply Enterprises; Dispatching Department; Technological Innovation; Team Building

\begin{abstract}
: the technological innovation management method of dispatching department in power supply enterprises is researched and practiced. Based on the technological innovation activities of dispatching department in power supply enterprises, the realization of building a harmonious team through activity carriers such as tackling hard-nut problems in science and technology, QC activity, thesis writing and patent application, etc. in technological innovation activities is researched and practiced.
\end{abstract}

\section{Introduction}

Dispatching department is the knowledge-intensive department in power supply enterprises, which generally includes power grid dispatching, relay protection, communication and automation specialty. Most employees in this department are with bachelor degree or above. The question has to be answered right in front of department managers is how to lead this high-quality staff team to achieve high-tech work tasks with high risk.

\section{Basic Approaches ${ }^{[1]}$}

(a) Make annual science and technology development strategy and specific policy objectives of technology work annually; The policy objectives of technological innovation are listed in annual policy objectives as those of safety production. Large scientific and technological research projects, mass QC and technological innovation activities, scientific papers and technical reports, patent application and staff training, etc. are included in policy objectives. Through making annual science and technology development strategy, the overall striving direction of the annual technological innovation task is determined at the beginning of the year, which ensures the realization of policy objectives of technological innovation annually.

(b) Make regulations on science and technology progress reward. Any research team or individual achieved outstanding achievements in technological innovation shall be amply rewarded both spiritually and materially. The reward regulation should be revised and improved during its execution in order to be more consistent with the actual situation, which inspires the initiative, enthusiasm and creativity of engineering technicians in technological innovation and ensures the prosperity of technological innovation task in terms of mechanism.

(c) The technological innovation task shall be included in the meeting agenda of leading group and the decisions concerning major events shall be made by the leading group collectively. Continuous motive power and planning are needed in large scientific and technological research projects, mass QC and technological innovation activities. There should be one person in the leading group appointed to manage the daily work of technological innovation, which includes scientific research project approval, project implementation, achievements verification, consolidation of application, etc. in terms of scientific and technological research projects; guidance on project approval, registration, project implementation, publication and evaluation of 
achievements, recommending to the superior, popularization and application, etc. in terms of mass QC and technological innovation activities; guidance on writing, modification of writings, recommending to the superior publication, etc. in terms of scientific papers. Nevertheless, some major events such as the application of project approval of major scientific and technological research projects and the establishment and revision of Regulations on Science and Technology Progress Reward shall be decided by the leading group collectively for the correctness of decisions.

(d) Technological innovation and staff training are two tasks that supplement each other. The demand for high-quality talents in technological innovation can push the training work forward. In the meanwhile, the generation of high-quality talents can accelerate the further development of technological innovation tasks. The staff training task should be implemented industriously, especially the basic knowledge and skills. Moreover, the training on knowledge and skills of QC, scientific papers writing, technological innovation and science and technology research should be developed further to cultivate the backbone and reserve talents of technological innovation. Hold QC knowledge lectures as well as inviting concerned experts and outstanding engineering technicians in QC task to give special reports. Hold training classes about scientific papers writing and new technology of power grid, through which to improve technological innovation ability of engineering technicians. The research team striving to make technological breakthrough should consist of different generations, in this way, there are old comrades experienced in technological innovation making technical checks in each research team as well as young and vigorous professional backbones and college graduates. Those young people are given the chance to undertake important tasks, which can ensure the fulfillment of each technological innovation research, at the same time, there must be some young people making progress through the whole process of research practice and becoming the backbone of the next research.

(e) The research team is organized according to the professional knowledge and skills required in scientific and technological research, the members in this team can be capable of most knowledge and skills required in the research and the director of the research can organize and carry out the research smoothly.

\section{Inspirations ${ }^{[1-4]}$}

(a) The fundamental guarantee of technological innovation task is the great attention and support from leaders. The director shall attach great importance to technological innovation task and offer support, preside over the formulating of policies and guidelines of technological innovation of dispatching and communication department.

(b) Technological innovation should be incorporated into daily work and be managed by one from the leading group, thus a normal mechanism can be formed.

(c) Those urgent problems in production practice shall be solved through science and technology research, as a result, the vitality of technological innovation task can be maintained.

(d) The difficult and key issues shall be considered as the main direction of mass QC and technological innovation activities, which helps comrades keep positive, active and cheerful. There is a vast reservoir of initiative and creativity among the broad masses, thus the key is how to give them correct guidance. The mass QC and technological innovation activities are carried out in terms of safety production, operation of electricity market, power grid construction and the improvement of quality and efficiency of work, etc. to solve those difficult and key issues at work. The QC and technological innovation activities are characterized by small scale, practicability, flexibility and novelty, which are suitable for the whole group to participate in. There is at least one QC team in each group and some are even more than two. The application of QC method has become the pet phrase and working standard. The concept "focusing on process, quality and substantial results" of QC and technological innovation activities is put forward by the leading group of the department duly, which makes the QC and technological innovation projects are closely related to production practice since the inception of the new century.

(e) Handle the relationship between technological innovation and safety production properly. The 
theoretical research, QC publication and verification on scientific and technological achievements of science and technology and QC project approval should be centralized in autumn and winter; all the regulations in safety production shall be abided by in daily science and technology and QC project implementation. Dispatching department serves as both production department and functional department, which undertakes the safety production of the department and power grid dispatching, relay protection, communication and automation specialty guidance work of the region. There are conflicts in time and staff in safety production and technological innovation work due to the dramatic increase of equipments and relative decrease of the number of staff. Those conflicts can be solved through proper arrangement of time and task distribution. Since there are many researches closely related to power grid, the compilation and execution of organization measures of security technology, the correctness and completeness of work ticket and omni-directional multi-process test on science and technology projects, etc. are emphasized in the research.

(f) Comprehensive quality of leaders in technological innovation

(1) Profound understanding and rich practical experience in chosen field

The scope of technology field differs in thousands of ways. Similarly, technology levels need to be improved differs. The leaders in technological innovation shall have profound understanding and rich practical experience and get further understanding on the past, present and future of the technology in his chosen field and find the bottleneck problems, in particular, they should have unique insights toward future development direction of the chosen field and high sensibility of the entry point of solving practical problems.

(2) Better understanding on national or industrial technological innovation policy

National or industrial technological innovation policy is the guidance programmatic document of technological innovation, which determines the attention, priority in investment distribution and policy support from nation or industry to the field. Leaders of technological innovation should get better understanding on the part in national or industrial technological innovation policy related to the chosen field. Currently, since the construction of extra-high voltage and smart power grids has been included into "the $12^{\text {th }}$ Five-Year Plan" government work report, therefore the extra-high voltage and smart power grids field can be funded preferentially and supported by policy from the nation or power industry in quite a long time in the future.

(3) Capable of putting forward technological innovation points

Coming up with technological innovation points is the key of the success of scientific research projects application. The improvement and research of new concept and technology, the introduction and application of advanced technology in other technical fields, the improvement of work efficiency and work quality, newly increased production value, energy-saving and cost-reducing, frontier basic theory, etc. can be put forward as technological innovation points.

(4) Capable of writing application materials of scientific research projects

The ability of writing application materials of scientific research projects is the basic ability that should be mastered by the leaders of technological innovation. Three major technical documents such as proposal for science and technology project, feasibility study report and letter of commitment of novelty search are included in the materials. The proposal for science and technology project mainly includes aspects such as necessity of the project, research situation home and abroad, major research contents, expected goal, research conditions qualified, cooperation intention, capital budget, etc. As for feasibility study report, the following aspects are contained such as the purpose and significance of the research, review on research level home and abroad, theoretical and practical foundation of research, content and scheme implemented of research, expected objectives, form of achievements, execution condition of partner unit and supporting engineering unit, the conditions of project unit, etc. For the letter of commitment of novelty search, the following items shall be contained such as the purpose, scope, subject term, major research content, innovation points, technical features and technical index of novelty search of the project. 


\section{Conclusion}

Technological innovation is the effective method of solving urgent problems in production practice which can help to establish a harmonious team. Furthermore, it is also an efficient carrier to achieve the highest pursuit of self-realization in behavioral science. Making great efforts to technological innovation work can get twofold results in improving divisional management with half the effort.

\section{References}

[1] Liu Debin, Zhang Xilin. On Managerial Experience in Technological Innovation of Dispatching Department of Power Supply Enterprises [J] China Electric Power Education, $2010,31: 235-236$.

[2] Wang Guoyou, Zhang Xilin. Building a Harmonious Team with Technological Innovation as Management Carrier [J] China Electric Power Education, 2011,12:61-62.

[3] Zhang Xilin, Xu Shouchen, Wang Shuo. On Comprehensive Quality and Personality charm of Technological Innovation Leaders [J] Human Resource of Electric Power,2011,9:37-39.

[4] Zhang Xilin, Wang Shuo. Two Key Points in Primary Level Management [J] China Power Enterprise Management ,2011,11:26-26. 